\title{
LESSON 88
}

Test your Skill

5 minutes.

MARGINS: Pica, 10-72; Elite, 15-85.

Keep the right margin as straight as possible.

Use double-line spacing.

$\mathrm{T} 18-\mathrm{SI} 1.28$

Postcard 2

PAPER : A6.

TARGET TIME: 5 minutes.

Letter 41

PAPER: A4.

TODAY'S DATE

TARGET TIME: 15 minutes.

Make any corrections you think fit and take one carbon copy. Address a suitable envelope. Try it in the semi-blocked style.
What decides where you shop and what you will

buy? Do you visit all the shops of a kind in your town and see what they all have to offer? Is your choice governed by quality or price and if so what is your test of price and quality?

The wise shopper will find out as much as can be found out about anything that he or she intends buying and there are many ways of doing this. The local library may well have copies of 'Which?' the Consumer Association publication which gives their conclusions after testing a wide range of goods in a detached unbiased manner.

If you buy from a reputable store you will be buying from a shop of proven quality and they will have a name to protect. If you buy branded goods, you will know next time if those goods are of good quality or not and so you will learn by experience those brands to buy and those to miss. Try asking your friends and in this way learn by the findings of others. After all it is your money at risk.
From The Binkton Manufacturing Company Limited, Deal Lane, Newbury, Berkshire. BE9 8NE

Ref. NA/NG To-day's date

I acknowledge the receipt of your application for the post of Office Junior. (Paragraph) You will hear from me again in the near future. Personnel Manager

To Miss Joan Stevens, 12 Forest Road, Newbury. BE7 INE
Rep GP/HS Jameds Typunitar Supplies, 116 Dam St., Combridge. CA 768 E Fot t. estention of Mr. R. W. Tames

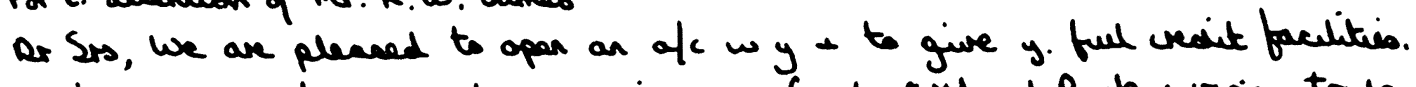
$T$. infenten. we hw. recerd. conearing y f. t. Midland Bank + verious trado

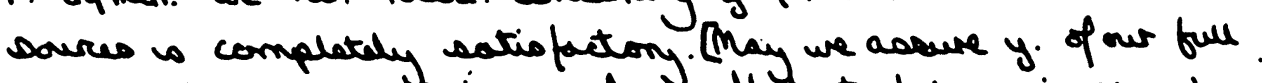
c-operatain at all taines + of act ffots to halp $y$. in securing nereand poffto through $t$. sale of ow goods. T. ffltet order $y$. ha placed w. wo is recurg. ow immediate abeantion + w. are packing wit samples. of our entive range of etationay. IIf y. ho. any quenes plance de not hasitate

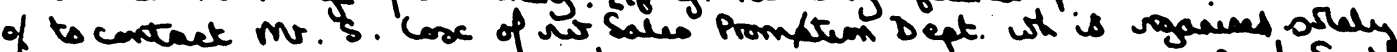

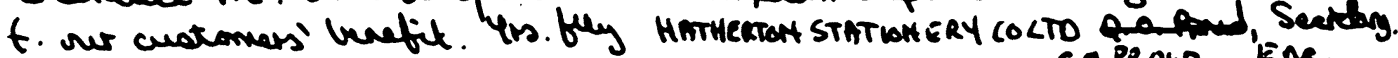
G.0. PR OUD Ene. 